\title{
Control of Codling Moth (Cydia Pomonella) Infestation Rate by Different Cultural Methods
}

\author{
Tajamul Nissar, Purnima Shrivastava
}

\begin{abstract}
The aim of the present work is to study the control of cultural techniques on the infestation rate and to calculate the population of codling moth from the orchards of Ladakh for the sake of convenience 4 orchards of Nurla village were selected from the Union territory of Ladakh and the different cultural methods were practiced in these orchards and in which the delta traps were installed to monitor the population of codling moth only for monitor purposes. Delta traps containing lures loaded with codlimone (E,E)-8,10-doddecadien-1-ol the sex attractant which attracts male moths towards trap. The orchards taken were practiced by different methods like orchard S1 (Bur lapping ), S2 (S sanitation),S3 (Bur lapping \& Sanitation ) and S4 with no method used (control ). According to the plan the visits were conducted and the result was taken to obtain the infestation rate and to analyze the population of codling moth from the selected orchards. The orchards with heavy infestation were measured in relation to the low-infested orchards of the same area containing equal number of trees. The population of the codling moth was also monitored during the three visits to these selected orchards in which the traps were installed and finally that was calculated. The table results clearly indicated that the orchard $\mathrm{S} 4$ were no method was practiced was heavily infested followed by S1 Bur lapping, S2 Sanitation, and very low infested S3 Bur lapping \& Sanitation. The traps catch was low in S3 were bur lapping and sanitation was done followed by S2 Sanitation, $\mathrm{S} 1$ bur lapping, and the highest catch was at $\mathrm{S} 4$ were no method was practiced. Finally the data from the orchards with high infestation and high trap catch was correlated with data from the orchards with low infestation and low trap catch. orchards
\end{abstract}

Index Terms - Moths, Infestation, Delta traps, Bur lapping, Sanitation.

\section{INTRODUCTION}

Codling moth (Cydia pomonella) is the most dangerous pest of apple fruits in all over the world. In India it has been seen only in ladakh union territory of India. The pest is damaging thousand crores rupees of fruits every year in almost every apple growing areas of ladakh. The pest is believed to enter to have entered into Ladakh from Pakistan and Afghanistan (North West border) and created havoc to the apple orchards of the region and a big menace to the growth and development of apple industry in the area.

Tajamul Nissar Research Scholar, Bhagwant University Sikar Road Ajmer, Rajasthan, India. Contact Number: $9906643135 / 7889629117$

Purnima Shrivastava, Dean Research, Bhagwant University Sikar Road Ajmer, Rajasthan, India Contact Number;9460707068
Presently this pest is the most persistent, destructive and difficult pest to control among the insect-pests of apple fruits (Stephen C.Walter 2009 in second edition of his book). This directly effects the economy of ladakh division. Though it can be controlled by different pesticides and methods. But the aim of the work was to control population of codling moth without using any insecticide so that other insects could not get effected( Moore, S 2012). Their are different kinds of insects in the apple orchards some are destructive but some are beneficial which plays an important role in pollination and are the predators of fruit damaging insects. Different methods were used during the work through which we can control the infestation caused by codling moth and could control the population of codling moth. The methods used during the work were very simple and are being already practiced in different countries. So it was necessary to practice these methods in ladakh and make people aware about these methods. The methods were fruit full and are now being practiced by the farmers of ladakh. The whole cultural methods were practiced in Nurla village of Leh because the orchards in Nurla are separated from each other at some distance. First methods was Trunk banding or Bur lapping method (G. J. R. Judd , M. G. T. Gardiner D. R 2005) during this method the gunny bag material was wrapped to the apple trees in the month of October 2018 and fruit fallen period because at that time temperature dips and the codling moth moves toward lower surface and loose barks for hibernation. Then the infestation rate was counted in another year 2019. Five traps were also installed to see the trap catch from the sites and after every months visits were done to these orchards these traps were installed before the first flight of the moth. The traps installed were loaded with codlimone (E,E)-8,10-doddecadien-1-ol the sex attractant which attracts male moths towards trap. When codling moth female attracts male towards itself for mating they secret codlimone so that codlimone was loaded in the lure inside the liner which then accordingly attracts male moths towards trap. When these moths move towards trap they get trapped on the linner containing sticky material. Then second method used was sanitation during which the orchard was fully sanitized by removing the fallen fruits from the orchard, the proper water system ,Pruning , Removal of unwanted grasses from the orchards etc. Five traps were also installed at these sites to monitor the population of codling moth. Third method is removal of loose barks from the apple trees. The moth after fruit fall or temperature decrease move towards loose barks 
and debris for the hibernation or diapauses. Then removing these loose barks under which the codling moth under goes hibernation should be removed. Five traps were also installed at these location to monitor the population of codling moth (BA Rather, Sushil Kumar et al 2016). Then fourth site was taken were all of these practices were done to see the effect of all of these methods on the population of codling moth. Five traps were also installed at this site to monitor the population of codling moth( P.-J. Charmillot D. Hofer D. Pasquier 2000) At all these sites the damage was taken and was correlated with each other. The trap catch taken at every visit was correlated with each other. The aim was to see the most effective method for the control of codling moth. Though it is not possible to get $100 \%$ control by using these methods but they play an important role to some extent. These methods when used separately could not show much more effect on the infestation rate of codling moth and the population of codling moth( Cydia pomonella) but when these methods are practised in one orchard proves much more effective not as of chemicals and pheromones but are very good. For the people of ladakh these results are quit good because they are not ready for any insecticide and other chemicals through which codling moth can be controlled because of religious ethics there as there is sin to kill any insect in Buddhism. These methods are not going to hurt anyone's sentiments. These methods are very easy to use and can easily practiced.

\section{MATERIAL AND METHODS}

Control of codling moth by using cultural techniques is very easy practice. The methods used are very simple and the material used is being already used by farmers in their day to day work. For bur lapping there is only need of gunny bag material which should be wrapped in two to three layers from base to middle of the tree trunk during Mid-August to September provided ideal shelter to for overwintering larvae which can be mechanically killed by unwrapping the bands or burnt down during November to April. . The fruits damaged by codling moth were counted in the orchard were the gunny bags were wrapped around the trunk of tree and the total number of fruits were counted and the fruits which were damaged were also counted to calculate the Damage of codling moth in the orchard .Four replicates were selected from site of bur lapping the and the one replicate was divided into four quadrants and the total number of fruits were counted and the infected fruits were counted to see the percentage of damage. The data was taken from these replicates during three visits in season to the orchards under examination. Five traps were also installed in the orchards to monitor the population of codling moth. During three visits number of moths trapped from these traps was also taken and the data was calculated. This also gives us the comparison between the different orchards the results was taken by using the statistical methods like Percentage, Median, histograms.
The infestation rate in each orchard was measure by Percentage of this formula;

$$
\text { Percentage }=\frac{\text { Number of Infected Fruits }}{\text { Total Number of Fruits Selected }} \times
$$

The sanitation in the orchards is very important because the when codling moth goes under pupation it needs adequate source of cover. It needs a suitable place for the pupation were moth could not feel any temperature or any other problem. It may go under soil or the debris around the soil or under the loose barks The another site selected in the village Nurla was taken into consideration to see the effect of sanitation on the infestation caused by codling moth. By removing sheltering debris from the vicinity of the base of the tree can deny cover. The unwanted trees present in the orchard were removed and the unwanted material present in the orchards was also removed. The fallen fruits, old gapes on trees, which could be the dwelling place for the codling moth were properly removed and gapes were filled with mud. Proper water system was also given to the orchards and the timing of water was also maintained. Continually the orchard was visited and the sanitation was maintained properly to get the effective results of sanitation on the infestation of codling moth. Procedure is same as of bur lapping site the four replicates were selected from the sanitized site and the one replicate was divided into four quadrants and the total number of fruits were counted and the infected fruits were counted to see the percentage of damage. The data taken was from replicates taken during three visits. Five traps were also installed in the orchards to monitor the population of codling moth. During three visits number of moths trapped from these traps was also taken and the data was calculated. The infestation rate in each orchard was measure by Percentage of this formula;

\section{Percentage $=\frac{\text { Number of Infected Fruits }}{\text { Total Number of Fruits Selected }} \times$ 100}

\section{Mean = $\frac{\text { sum of observations }}{\text { total number of observations }}$}

The loose barks were also removed from the orchards with the help of blade. It was done before fruit fallen and before winter because after the fruit fallen the codling moth will move towards the loose barks of the tree where it will spend its resting cycle or diapauses. But the barks were removed before the movement of codling moth from the trees and was fully sanitized.

Pruning is cutting is one of the most important methods practiced in Leh. The pruning done at the site plays a vital role to control the infestation caused by codling moth and the population of codling moth. The people of ladakh were unaware about the pruning system and were not ready for pruning and it was the main important thing to make them 
prepare for pruning and show them proper techniques. The site were pruning was done was taken under observation with the orchards under sanitation. The equipments used for pruning are Moving lawn which is used to reach up to top of the tree, Secateurs used to cut the unwanted branches of the tree, Loppers used to cut the thicker stem and branch of the tree, Tree pruning saw also used to cut the thicker branches of the tree. The infestation rate was taken by this method Four replicates were selected from the sanitized site and the one replicate was divided into four quadrants and the total number of fruits were counted and the infected fruits were counted to see the percentage of damage. The data taken was from replicates taken during three visits. Five traps were installed at $4 \mathrm{mtr}$ height at every location and were put under surveillance to meet the aim of work. After every 1 month up to September three visit were done to these orchards to count the moths trapped in these orchards. Then finally the total catch of moths trapped from these orchards was taken to see the highest moth caught place. Traps used are homemade and inexpensive and can be easily used in the field. The purpose of hanging a codling moth trap and lure in your trees is to attract the moths from your fruit into the lure. where they drown get attached to sticky material and got trapped inside the trap and became unable to move from the trap. After each 1 month the data from these traps was taken and the sticky material present in them was changed to maintain its fluidity. The five traps were installed in North East West and South directions and one trap at centre of the apple orchard. The total no of moths after September will give us the exact figure and number of moths.

\section{RESULT AND DISCUSSION}

The codling moth is the most dangerous pest of apple in the ladakh region of Jammu and Kashmir. We have selected only few sites from Nurla village of Leh ladakh region i.e. Kargil like( Nurla, S1 ( Bur lapping ), Nurla S2 ( Sanitation ), Nurla S3 ( Bur lapping and sanitation), Nurla S4 (Control). The S1 site was used for bur lapping, The loose barks were also removed from the site $\mathrm{S} 1$. It was the site were only bur lapping was done to the orchard at the Nurla. It was seen that the larva were present in the gunny bags after fruit fall in bulk amount and then these larva's were destroyed and the damage taken from the orchard was almost $60 \%$ and rest of the $40 \%$ was safe and then the data was compared with other parameters and the trap catch data was also taken. The traps catch was high as compare to other two parameters. The orchards selected from the sites contain different variety of apples like kashur kushu, kar kishu, red delicious, local variety of apple. These are the varieties of apple in the orchards of ladakh which are being attacked by the codling moth(Cydia pomonella). Five traps were installed at each and every site. The traps were installed at four corners in one by one manner. Liners were changed after every 1 month of visit. The trap catch was taken from June to September of 2019.The data of every visit was taken and was calculate at the end .Then after each 1 month visit was conducted to the orchards for the data collection. The data taken from these sites has been tabulated below.

Five traps were installed at every site and the liners were continuously changer to maintain the fluidity of the trap. Three visits were done from June to September so that the exact number of moths can be taken from these orchards. Hence the total numbers of moths trapped from these selected orchards were counted. So that we can see the data taken and correlate that data with the infestation rate in the orchards.

S2 site of Nurla was put under examination and the proper sanitation of the orchard was done like, Removal of fallen fruits from the orchard, Proper pruning of the orchard. And the gapes on trees were filled with mud, Removal of unwanted trees and other material from the trees was done. The damage taken was quit good as compare to the bur lapping and $50 \%$ of fruits were seen damaged and the rest of $50 \%$ were safe. The damage was taken from the four replicates in the orchard These Replicates were divided into four quadrants and from every quadrants fruits were counted and the damaged and not damaged fruits were also count to calculate the fruit damage. Five traps were also installed here to see the trap catch from the orchards taken under examination for sanitation. The trap catch was low as compare to the bur lapping site and was also correlated with the other sites.

S3 site of Nurla was also taken and both the practices like bur lapping ( gunny bags ), Sanitation were done to this orchard. The result taken was quit good as compare to other practices. The each and every process of cultural method was done in this orchard like bur lapping, sanitation, removal of loose barks, removal of fallen fruits, filling of gapes, pruning of trees and the result taken was very good as compare to the other sites. The damage taken was almost $17 \%$ and the rest of the fruits were good (83\%). That gives an clear indication that the orchard of apple should be properly maintained and properly sanitized. The proper cultural methods can give us the good results. Thus doing these practices we can save almost $83 \%$ of fruits and that is quit good result. The traps installed in this site was having very low trap catch as compare to other three site. That also shows your result that low the trap catch low the damage in you orchard. The process of all cultural methods was showed to the farmers of ladakh and they were impresses and are now doing all the cultural methods in their orchards.

S4 site of Nurla was taken as a control site it was taken under examination. In this orchard no cultural, chemical and any other process was done it was taken as such to see the control of cultural practices in other orchards. The orchard was not bur lapped, sanitized, and not any kind of other practice was done in this orchards. The taken from this orchard was different from the orchards under cultural control. The infestation rate was very high as compare to other orchards almost $90 \%$ fruits were damaged only $10 \%$ of fruits were safe. The data is written below. The trap catch in this orchard 
was also very high as compare to the other orchards. This difference of cultural control shown us the effect of cultural control in the orchards of ladakh. The data from all the orchards is written below and we can easily see the most effective process of cultural control for the codling moth infestation is to use all the cultural methods in your orchards. Then it is not necessary to spray your orchard with any of the pesticide if you will do all the cultural methods in your orchard. The results taken shows us that the orchard S4 is highly damaged followed by the $\mathrm{S} 1$ the orchard under examination for bur lapping, followed by the $S 2$ the orchard under examination of sanitation, and in the last S3 the orchard were all the cultural techniques were used. The S3 was seen with very low infestation rate. The all the methods used in these site shows us that if we do all the cultural techniques in our orchards we can save almost $85 \%$ f fruits in our orchards.

\section{INFESTATION CAUSED BY CODLING MOTH IN CULTURAL CONTROL SITES}

\begin{tabular}{|l|l|l|l|l|}
\hline VISITS & \multicolumn{4}{|l|}{ Mean Pest Infestation (\%) } \\
\hline $\begin{array}{l}\text { Test } \\
\text { Sites }\end{array}$ & S1 & S2 & S3 & S4 \\
\hline \hline $\begin{array}{l}\text { VISIT } \\
\mathbf{1}\end{array}$ & 13.59 & 13.73 & $4.83 \%$ & $\begin{array}{l}14.25 \\
\%\end{array}$ \\
\hline $\begin{array}{l}\text { VISIT } \\
\mathbf{2}\end{array}$ & $\begin{array}{l}23.23 \\
\%\end{array}$ & $21.46 \%$ & $9.83 \%$ & $\begin{array}{l}44.72 \\
\%\end{array}$ \\
\hline $\begin{array}{l}\text { VISIT } \\
\mathbf{3}\end{array}$ & $\begin{array}{l}51.94 \\
\%\end{array}$ & $\begin{array}{l}42.115 \\
\%\end{array}$ & $\begin{array}{l}15.24 \\
\%\end{array}$ & $\begin{array}{l}82.84 \\
\%\end{array}$ \\
\hline $\begin{array}{l}\text { Sub } \\
\text { mean }\end{array}$ & 88.76 & 77.30 & 29.9 & 141.81 \\
\hline Mean & \multicolumn{5}{|c|}{84.44} \\
\hline
\end{tabular}

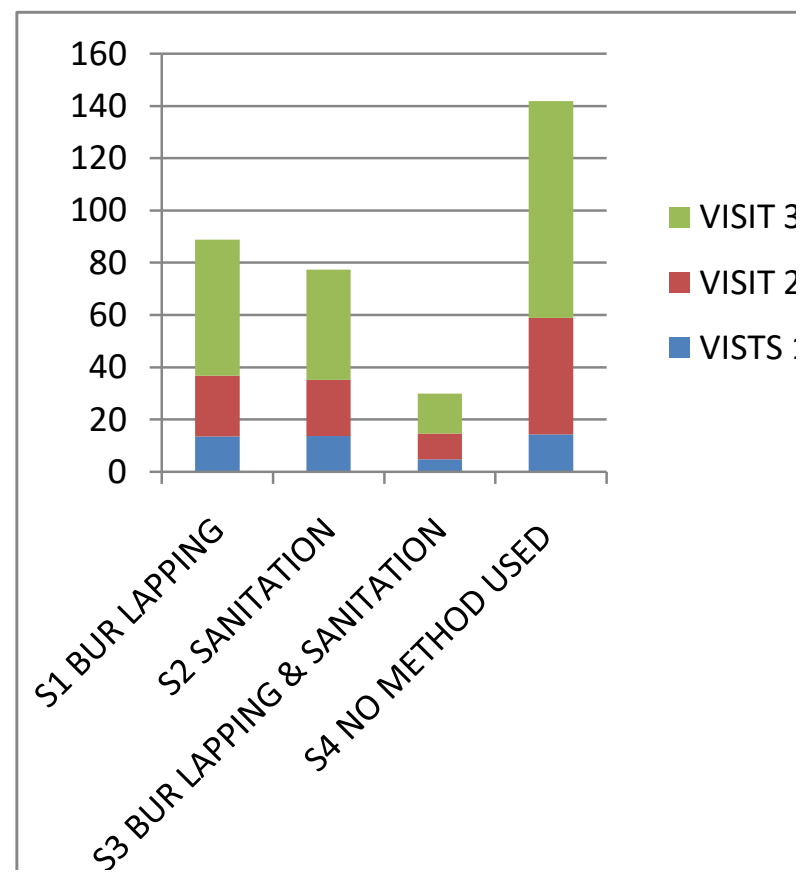

\section{INFESTATION RATE IN THE ORCHARDS UNDER} CULTURAL CONTROL

We can easily see that the orchard S3 under bur lapping and sanitation is the least damages and the orchard with S4 under no method used is highest damaged. The damage can be easily seen in the chart above. Which shows that the orchard which was taken into examination for all the techniques of cultural method S3 was least damaged in all the three visits followed by the orchards S2 under sanitation and followed by the orchard S1 under the examination of bur lapping then finally the orchard S4 were no practice of cultural method was used was highly damages The orchards under the bur lapin and under the sanitation are also least damaged as compare to the orchard under no cultural method used. This implies that the orchards could be controlled by the use of cultural methods. But those methods should be used properly and one should have a proper knowledge how these process could be used.

The trap catch was also seen from the orchards under cultural control to monitor the population of codling moth in the orchards under cultural method examination. The data was taken in three visits mad to the orchard in different moth to calculate the trap catch.

\section{MOTHS CATCHED FROM CULTURAL SITES}

\begin{tabular}{|l|l|l|l|l|}
\hline & \multicolumn{4}{|l|}{ Average number of moths trapped. } \\
\hline $\begin{array}{l}\text { Test } \\
\text { Sites }\end{array}$ & S1 & S2 & S3 & S4 \\
\hline $\begin{array}{l}\text { Visit } \\
\mathbf{1}\end{array}$ & 10.4 & 9.8 & 3.00 & 12.4 \\
\hline $\begin{array}{l}\text { Visit } \\
\mathbf{2}\end{array}$ & 16.00 & 15.00 & 4.6 & 33.3 \\
\hline $\begin{array}{l}\text { Visit } \\
\mathbf{3}\end{array}$ & 31.4 & 29.4 & 8.82 & 41.4 \\
\hline $\begin{array}{l}\text { Sub } \\
\text { mean }\end{array}$ & 57.8 & 54.2 & 16.42 & 87.1 \\
\hline $\begin{array}{l}\text { Mea } \\
\text { nea }\end{array}$ & \multicolumn{5}{|l}{} \\
\hline
\end{tabular}

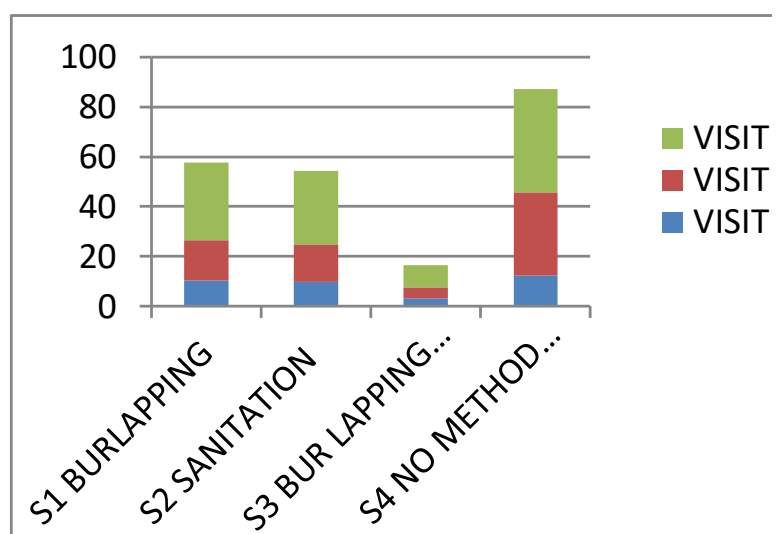




\section{TABLE SHOWING NUMBER OF MOTHS TRAPED FROM EACH SITE}

From the above table it is now clear that the highest number of moths were trapped from the site S4 were no method was used followed by the $\mathrm{S} 1$ were bur lapping was done followed by $\mathrm{S} 2$ were sanitation of orchards was done and the lowest catch of codling moth in each three visits was counted in S3 were all the methods of cultural control was done. This indicates that if all the cultural methods will be done in the orchard the infestation rate will be low and the trap catch also will be low. The trap catch in S3 was low due to use of each and every cultural method used there like bur lapping, sanitation

, remove of fallen fruits, remove of loose barks, pruning etc. All these methods if used properly can reduce the fruit damage in your orchards.

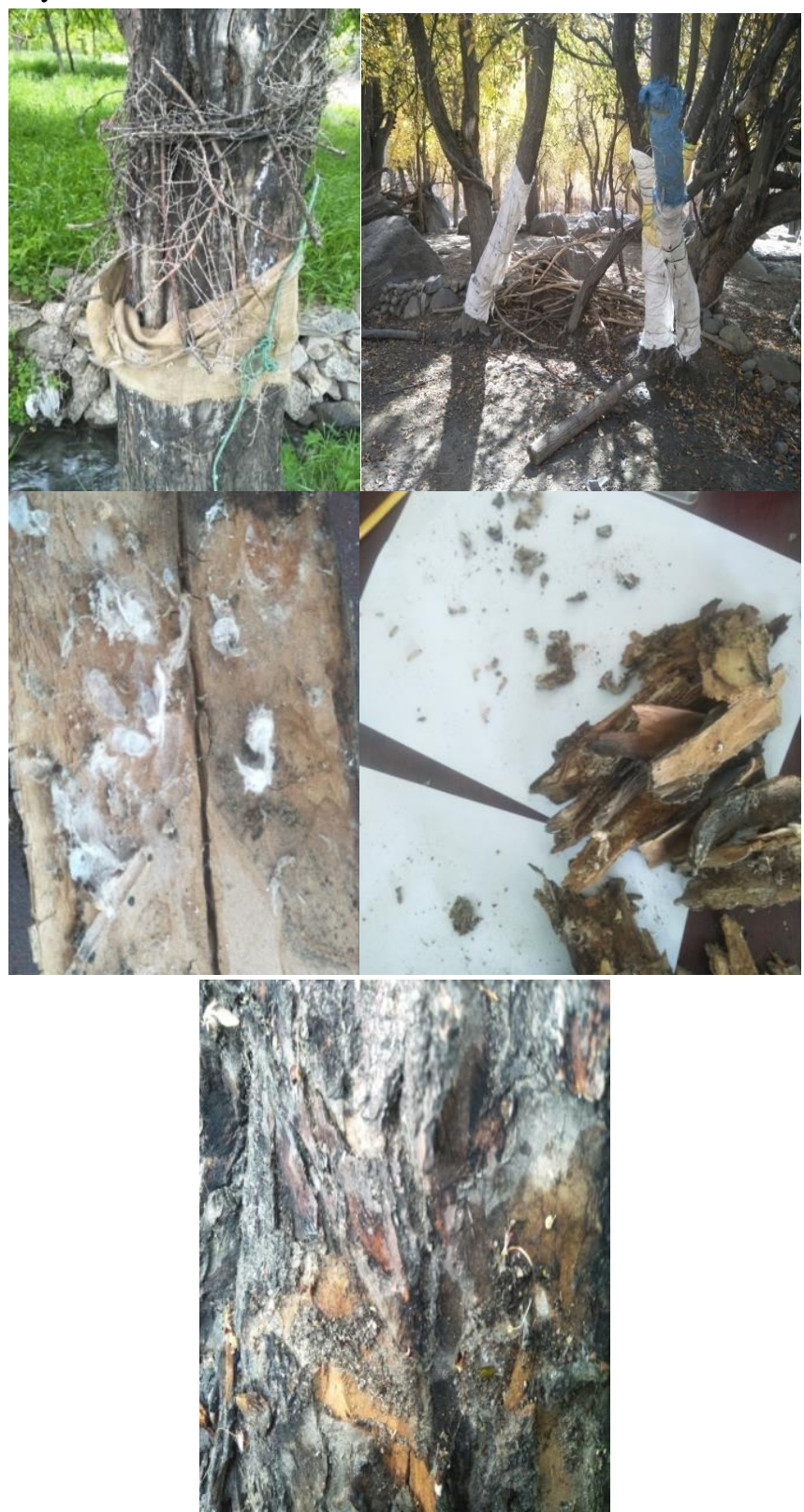

BUR LAPPING OF TREES \& REMOVAL OF LOOSE BARKS

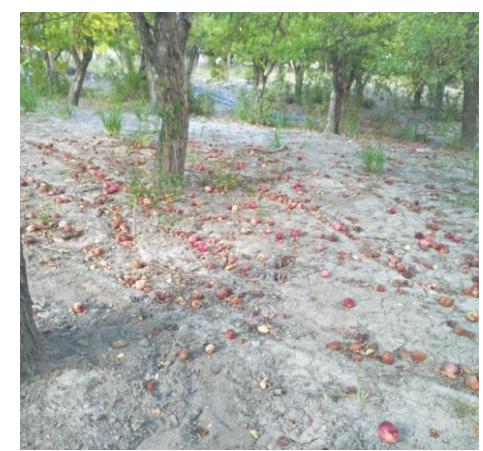

FALLEN FRUITS

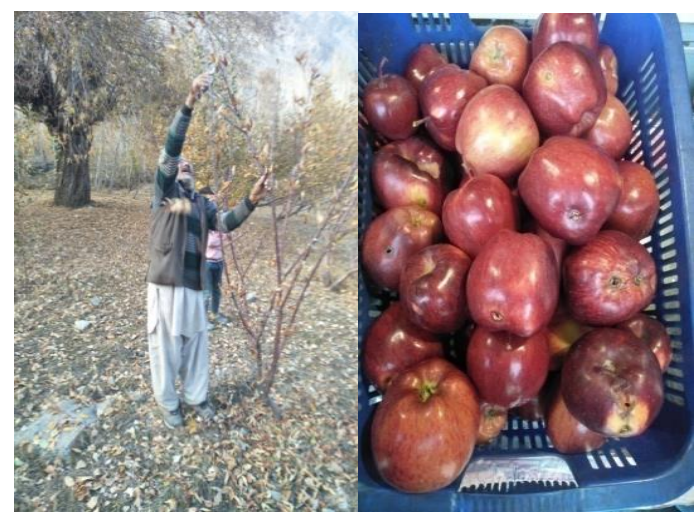

PRUNING OF TREES \& DAMAGED FRUITS

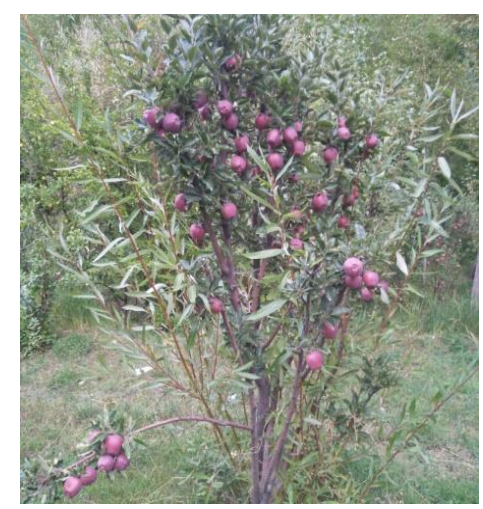

\section{ORCHARDS WITH ALL CULTURAL METHODS}

\section{CONCLUSION}

The work under taken was completed in the two years and it was concluded that codling moth (Cydia pomonella) is a major apple pest in ladakh division of Jammu and Kashmir attacking every variety of apple in ladakh division. The aim of the project was to control the infestation caused by codling moth through cultural methods. Different cultural methods were practiced in the Village Nurla. The for sites in Nurla were selected, S1 Bur lapping, S2 Sanitation ,S3 Bur lapping and sanitation and S4 which was taken untreated to see the effect of different methods used. The monitoring of codling moth was also studied in the project. Codling moth was monitored by the traps containing lure (attractant of codling moth) were installed at the different orchards at different locations. Moths were trapped from different sites and were calculated in which highest number of moths were caught from, which indicated that the place with highest trap catch will be highly infected. 
To calculate the damage in these sites four replicates were taken in the site and one replicate was divided into four quadrants and from ach quadrant total number of fruits and damaged fruits were calculated to see the damage level at every location. Three visits were done during the session 2019. The damage was clearly seen between orchards which included the highest damage was at S4 followed by S1, S2, and S3. This study is useful in enumerating our damage and will verily provide workers an edge in exploring further reasons and control methods for the said pest. In future it will serve the purpose of researchers for decades.

\section{REFERENCES}

[1] . P.-J. Charmillot D. Hofer D. Pasquier 2000. Attract and kill: a new method for control of the codling moth Cydia pomonella. Entomologia Experimentalis et Applicata 94: 211-216, 2000

[2]. S. Moore ; Hattingh, V.2012.A review of current pre-harvest control options for false codling moth in citrus in southern Africa. SA Fruit Journal 2012 Vol.11 No.4 pp.82-85 ref.35

[3]. G. J. R. Judd M. G. T. Gardiner D. R 1997. Thomson 2003. Control of codling moth in organically-managed apple orchards by combining pheromone-mediated mating disruption, post-harvest fruit removal and tree banding. Entomologia Experimentalis et Applicata 83: 137-146, 1997.

[4]. B Hussain etal 2014.Monitoring and mass trapping of codling moth by use of pheromone baited traps in ladakh,india.international journal of fruit science $15(1), 1-9,2015$

[5]., R.A Malik ., A.A. Punjabi, and A.A. Bhat. 1972. Survey study of insect and non-insect pests in Kashmir. Horticulture 3: 29-44.

[6]. C. H. Krupke, B. D. Roitberg, G.J.R. Judd 2002. Field and Laboratory Responses of Male Codling Moth (Lepidoptera: Tortricidae) to a Pheromone-Based Attract-and-Kill Strategy. Environmental Entomology, Volume 31, Issue 2, 1 April 2002, Pages 189-197,

[7]. BA.Rather 2017.Codling moth and its area wide integrated pest management in kargil. ladakh.journal of hill agriculture 8(3)329-333, 2017 [8]. G. J. R. Judd , M. G. T. Gardiner D. R 2005. Towards eradication of codling moth in British Columbia by complimentary actions of mating disruption, tree banding and sterile insect technique: Five-year study in organic orchards. Journal of Crop Protection Volume 24, Issue 8, August 2005, Pages 718-733

[9]. T Boivin,J Chadoeuf,Jean-Charles Bouvier etal 2005.Modelling the interaction between phenology and insecticides resistance gene in the codling moth( Cydia pomonella).Pest Management science 61;53-67(2005).

[10]. BA Rather, S. Kumar etal 2016. Determination of installation heights for pheromone traps in apple canopy used in mass trapping of codling moth (Cydia pomonella) in kargil leh.ladakh.Advance in life science.ISSN.2278-3849, 293-295,2016

[11]. D E.Farnandez, L.Cichon etal 2010.Comparison of lures loaded with codlimone and pear ester for capturing codling moth, Cydia pomonella, in apple and pear orchards using mating disruption. Journal of insect science ISSN; 1536-2442 VOL10 NUMBER139
[12]. P. Witzgall, L. Stelinski, et al 2008. Codling Moth Management and Chemical Ecology. Annual Review of Entomology Vol. 53:503-522 (Volume publication date January 2008)

[13]. AD.Pawar,NC Tuhan,etal 1981.suppression of codling moth Cydia pomonella (L) by sex pheromone mass trapping of males in ladaakh.indian journal of plant protection 9 (1),94-99-1981

[14]. A.D Pawar,., N.C. Tuhan, S. Balsubramanian, and M. Parry. 1981. Distribution, damage and biology of codling moth, Cydia pomonella (L). Ind. J. Plant Protection 10: 111-114.

[15]. L. A. Lacey 2008. Codling moth granulovirus: a comprehensive review. Journal of Biocontrol Science and Technology Volume 18, 2008 - Issue 7

[16]. P. Witzgall, D. Thomson, L. Stelinski, 2008. Codling moth management and chemical ecology. The annual review of entomology.

[17]. M. Murray, D Alston 2015. Intermountain Commercial Tree Fruit Production Guide. A publication by Utah State University, Colorado State University, and University of Idaho chapter 1.page 1-18.

[18]. P. Trematerra. 1993. On the possibility of mass-trapping Synanthedon myopaeformis Bkh. (Lep. Sesiidae). J. Appl. Entomol.115: 47-483.

[19]. J. Katan 2004. Role of cultural practices for the managment of soiborne pathogens in intensive horticultural systems . ISHS Acta Horticultural 635.

[20]. O Basil. Been 1995. Integrated pest management for the control of lethal yellowing: quarantine, cultural practices and optimal use of hybrids. Research and Practlcal Aspects, 101-109.

[21]. W.Cranshaw \& R.Hammon 2013. Codling moth control ine home planting. Colorado state university.Extension. 6/13.Fact sheet no,5.613.

[22]. C. R. Cutright, T. H. Parks 1934.The Codling Moth and Its Control. Bulletin of the agricultural collage extension service, The Ohio state university..No 148 May 8 and June 30, 1914 